\title{
Stage IB Vulvar Cancer AJCC v8
}

National Cancer Institute

\section{Source}

National Cancer Institute. Stage IB Vulvar Cancer AJCC v8. NCI Thesaurus. Code

C139621.

Stage IB includes: T1b, N0, M0. T1 b: Lesion measuring more than $2 \mathrm{~cm}$, or any size with stromal invasion of more than $1.0 \mathrm{~mm}$, confined to the vulva and/or perineum. N0: No regional lymph node metastasis. M0: No distant metastasis. (AJCC 8th Ed.) 